\title{
Incorporating depth into habitat use descriptions for sailfish Istiophorus platypterus and habitat overlap with other billfishes in the western North Atlantic
}

\author{
Walter J. Bubley ${ }^{1 *}$, Benjamin Galuardi ${ }^{2}$, Amy W. Dukes ${ }^{1}$, Wallace E. Jenkins ${ }^{1}$ \\ ${ }^{1}$ South Carolina Department of Natural Resources, Marine Resources Division, Charleston, SC 29412, USA \\ ${ }^{2}$ School of Marine Science and Technology, University of Massachusetts Dartmouth, Fairhaven, MA 02719, USA
}

\begin{abstract}
The sailfish Istiophorus platypterus is a circumglobal billfish species. It is commonly targeted in recreational fisheries and caught as by-catch in commercial fisheries, and therefore fisheries management would benefit from an enhanced understanding of basic patterns of the species' daily and seasonal movements. Between 2002 and 2007, 87 billfish were tagged with popoff satellite archival tags in the Atlantic waters off the coast of South Carolina, USA, including sailfish ( $\mathrm{n}=54)$, blue marlin Makaira nigricans $(\mathrm{n}=15)$, and white marlin Kajikia albida $(\mathrm{n}=18)$. Only fish meeting specific tag program criteria and length of tag attachment were selected for further analysis (sailfish, $\mathrm{n}=19$; blue marlin, $\mathrm{n}=4$; white marlin, $\mathrm{n}=3$ ). Differential horizontal and vertical movement patterns were observed within sailfish by season. Two- and three-dimensional (3D) analyses showed differential spatial niche use by sailfish. Among the istiophorid species, 3D analysis showed less overlap when occupying similar horizontal areas. The results from this study, in conjunction with similar studies from other areas, provide a better understanding of habitat usage that can be applied to address uncertainties in ecology or management, such as characterization of stock structure, identifying potential spawning habitat or intra-specific competition, providing correction factors for indices of abundance, and characterizing vulnerability to fishing gear.
\end{abstract}

KEY WORDS: Pop-off satellite archival tag · Three-dimensional habitat utilization · White marlin • Blue marlin

\section{INTRODUCTION}

The sailfish Istiophorus platypterus is a relatively large and highly migratory species that has a circumglobal distribution. There are multiple stocks in the Atlantic Ocean, including one in the western North Atlantic (Collette et al. 2006, ICCAT 2016). It is a highly prized recreational fish and a common bycatch species in pelagic longline fisheries, but the stock status in the Atlantic is uncertain (ICCAT 2016). A basic understanding of movement patterns and vertical habitat use of sailfish in the western North Atlantic is essential for improved assessments in the future (Restrepo et al. 2003, Lynch et al. 2012, Lam et al. 2016).

\footnotetext{
*Corresponding author: bubleyw@dnr.sc.gov
}

Ortiz et al. (2003) compiled tag/release and recapture efforts of the major constituent-based tagging programs globally using streamer tags, and although sailfish had more records than other billfish species, their return rates were $<2 \%$, leaving large gaps in our understanding of their movement patterns. Based on recaptures of sailfish in the same location/ time of year, it is thought that their horizontal movements are either cyclical annually and/or that they are relatively site fidelic throughout the year (Ortiz et al. 2003, Orbesen et al. 2008). Furthermore, by providing only information about tagging and recapture locations, conventional streamer tags do not allow the collection of fine-scale data on spatial movements between these 2 locations, including vertical distri-

() The authors 2020. Open Access under Creative Commons by Attribution Licence. Use, distribution and reproduction are unrestricted. Authors and original publication must be credited. 
butions. An improved characterization of general habitat and movement requires a finer spatiotemporal resolution than that provided by streamer tags in the horizontal direction. Because these animals live in a 3-dimensional (3D) environment, it is sensible to include vertical habitat information (i.e. depth) in analyses whenever possible.

Pop-off satellite archival tags (PSATs) provide a means of collecting finer resolution horizontal information, while concurrently collecting vertical movement data for a variety of highly migratory fishes (Sedberry \& Loefer 2001, Hoolihan et al. 2009, Galuardi et al. 2010). A number of studies have utilized these tags in recent years to examine sailfish movement patterns in the western North Atlantic, and while the range of this species extends as far north as the Gulf of Maine at latitudes greater than $41^{\circ} \mathrm{N}$ (Carpenter 2002), none of these tags have been deployed north of $26^{\circ} \mathrm{N}$. These studies have also focused on characterizing horizontal and vertical movement patterns separately, potentially obscuring complex behaviors (Zhu \& Weng 2007, Simpfendorfer et al. 2012).

Based on fishery-dependent data from a recreational tournament fishery conducted off the coast of South Carolina, USA, during the months of May-July between 2000 and 2019 (http://govcup.dnr.sc.gov/ Standings/Catch/), sailfish are commonly caught in areas north of $26^{\circ} \mathrm{N}$, concurrently with other istiophorids (i.e. blue marlin Makaira nigricans and white marlin Kajikia albida). While these species overlap spatially during this time, they are known to have differing migration patterns throughout the year, with sailfish having more localized and coastal movements than white and blue marlin (Ortiz et al. 2003).

The current study was part of a broad effort to examine important habitat of multiple pelagic species, including billfish, managed under the Highly Migratory Species Fishery Management Plan by the National Marine Fisheries Service, that occur in the Charleston Bump Complex off the southeastern USA (Loefer et al. 2007). The goal was to identify spatial and temporal habitat use that can be related to the pelagic longline fishery to determine potential gear interactions and examine the effectiveness of seasonal and area closures of the fishery. The Charleston Bump Complex consists of the topographic and oceanographic features, the Charleston Bump and the Charleston Gyre, respectively. The topographic feature is located between $31.5^{\circ}$ and $32^{\circ} \mathrm{N}$ and between $78^{\circ}$ and $79.5^{\circ} \mathrm{W}, 130-160 \mathrm{~km}$ southeast of Charleston, South Carolina (Brooks \& Bane 1978).

We utilized PSATs to simultaneously characterize the horizontal and vertical movements of sailfish among seasons. Spatial use patterns were also compared between sailfish and 2 co-occurring istiophorid species, blue and white marlins. We examined these patterns in both 2 and 3 dimensions to explore the variability in spatial overlap of species potentially competing for resources, using a traditional as well as a more ecologically realistic approach, respectively. Three-dimensional spatial characterization is more ecologically realistic because these species occupy multiple depths in the water column, which is informative for ecological processes. Overall, the results from our study, in conjunction with similar studies from other areas, provide a better understanding of habitat usage that can be applied to address uncertainties in ecology or management, such as characterization of stock structure, identifying potential spawning habitat or inter-specific competition, providing correction factors for indices of abundance, and characterizing vulnerability to fishing gear.

\section{MATERIALS AND METHODS}

\subsection{Field methods}

In this study, PSATs (PTT-100 archival pop-up tags; Microwave Telemetry) were used. The tags were equipped with pressure (depth), temperature, and light sensors. There were 2 sampling intervals for the larger study covering numerous pelagic species: a high rate, which sampled once every $4 \mathrm{~min}$, and a standard rate, which sampled once $\mathrm{h}^{-1}$. The high-rate tag provided more fine-scale movements due to the higher frequency of sampling but is less useful for larger scale horizontal movement patterns due to restrictions in geolocation data and memory/battery limitations allowing a maximum of $30 \mathrm{~d}$ prior to detaching. Samples from all PSATs were taken until the programmed release date from 30-240 d after the date of tag activation and deployment (see Table 1).

Sailfish, blue marlin, and white marlin tagged for this study were caught from recreational sport-fishing vessels between 2003 and 2006 that were targeting istiophorids, between the months of May and August. To minimize injury and stress, fishes were not removed from the water during tagging and were released by removing the hook, when possible, or cutting the monofilament hook leader within a few $\mathrm{cm}$ of the hook. Tags were attached by harpooning a $6.25 \mathrm{~cm}$ titanium M-type dart anchor into the dorsal musculature approximately $5 \mathrm{~cm}$ below the midline of the base of the dorsal fin. The anchors were inserted using a $20 \mathrm{~cm}$ titanium tagging needle pro- 
tected by a $6 \mathrm{~cm}$ diameter rubber stopper limiting penetration depth to $12 \mathrm{~cm}$. Tags were tethered to the anchors with $30 \mathrm{~cm}$ of $1.66 \mathrm{~mm}$ diameter fluorocarbon monofilament (100 kg tensile strength). Monofilament was attached at either end with stainless steel crimps covered with adhesive-lined polyolefin heat shrink tubing. Each tag leader had a $10 \mathrm{~cm}$ piece of polyolefin heat-shrink tubing attached to the distal end of the leader that contained printed tag return information. Tags were labeled with this information to aid in the return of satellite tags from animals that may have been recaptured prior to tag release. Deployment location and environmental parameters such as depth $(\mathrm{m})$ and sea surface temperature $\left({ }^{\circ} \mathrm{C}\right)$ were recorded at the time and date of tagging. Because the fish were not removed from the water, an actual measurement of length could not be taken, but an estimate of lower jaw fork length was recorded in inches (and converted to $\mathrm{cm}$ ) for tagged fish starting in 2004.

\subsection{Analysis}

All analyses were performed using R v.3.6.0 ( $\mathrm{R}$ Core Team 2019). Only standard-rate tags attached for greater than $2 \mathrm{wk}$ were analyzed. The high-rate tags have limitations in terms of memory/battery as well as light level data taken for geolocations and are more suitable for high resolution and short time periods; these were not appropriate for long-term tagging studies. The tags calculated sunrise and sunset times based on light readings from the tag, which were processed into geolocations by the manufacturer. These geolocations were then filtered using state space Kalman filter models to estimate the most likely locations of tagged fish during the time at liberty. When suitable temperature data from the tag was present, a temperature inclusive model, 'ukfsst', was utilized (Lam et al. 2008, Nielsen et al. 2012). When temperature was unavailable, or when the model would not converge using 'ukfsst', a light-only model, 'kftrack' was used (Sibert et al. 2003). For days with no light data, positions were interpolated using the results of the 'ukfsst'/'kftrack' output in a subsequent state space model, CRAWL (Johnson et al. 2008). For each model run, uncertainty in position was estimated (Sibert et al. 2003, Nielsen \& Sibert 2007, Lam et al. 2008). This was then used to perform a bathymetric correction using the R package 'analyzepsat' (Galuardi 2010). The bathymetric correction utilized ETOPO1 data (Amante \& Eakins 2009) through randomly sampling 300 points within the estimated uncertainty bounds of each day's estimated position. Points at depths shallower than the maximum daily depth were discarded. A final position, hereafter referred to as the mean daily location, was estimated based on the previous day's final position and the resampled depths that met the daily depth criteria (Galuardi et al. 2010).

Since there was a relatively large sample size of tag attachments throughout the year for sailfish compared to the other billfish species, seasonal differences were examined for sailfish only. Because of the variable times at liberty and differing sample sizes between species, inter-species comparisons were only examined from June-August, as these months had the greatest consistency of data recording across all tagged species.

Displacement and distance travelled were calculated using the 'distHaversine' function of the R package 'geosphere' (Hijmans 2015). This calculated the shortest distances between 2 points using the greatcircle-distance method to quantify horizontal movements. Displacement of the individual fish, which is analogous to information obtained from streamer tagging, was determined by calculating the distance between the deployment and pop-off location, regardless of the movement between those events. Distance travelled was calculated as the sum of the daily distances travelled using the mean daily locations from the filtered, light-based geolocation estimates. Since there is error associated with each mean daily location (with exception of the tagging and pop-off locations), this measurement serves as a proxy rather than a true distance travelled.

Vertical diel movement patterns were examined between and within species. Hours of daylight were determined using the 'sunriset' function in the $\mathrm{R}$ package 'maptools' (Bivand \& Lewin-Koh 2015) to calculate sunrise and sunset times based on the mean daily location and date. Data points during the crepuscular period ( $\pm 1 \mathrm{~h}$ of sunrise and sunset) were removed as this transition period could create noise in examining diel differences, as well as provide buffer for the error associated with the estimated locations. Depth at time was then assigned into hours of daylight ( $1 \mathrm{~h}$ after sunrise to $1 \mathrm{~h}$ prior to sunset) and night (1 $\mathrm{h}$ after sunset to $1 \mathrm{~h}$ prior to sunrise). Mean daily, day, and night depths were calculated for each fish for analysis to remove autocorrelative effects. If data were normally distributed, summary metrics were derived using parametric approaches (ANOVA followed with a Tukey's post hoc test). Otherwise, nonparametric approaches were utilized (Kolmogorov-Smirnov test). Three metrics were examined: daily diel depth 
differences for sailfish, seasonal diel differences for sailfish, and diel depth differences among species between June and August.

To examine horizontal and vertical space use, 2D (latitude and longitude) and 3D (latitude, longitude, and depth) utilization distributions (UDs) were calculated, by species, using modified methods from Simpfendorfer et al. (2012) and the R package 'ks' (Duong 2015). Horizontal data (latitude and longitude) were converted to North American Albers Equal Area Conic projection to match the units of the bathymetric data $(\mathrm{m})$ for 3D analysis.

The plug-in bandwidth selector was used to determine the smoothing factor matrix to examine the effect of reduced complexity of the UD in kernel estimation and better reflect uncertainty associated with the location estimates. Because both 2D and 3D UDs were being produced and comparisons were being made between them, a common multiplier was determined. The optimal value was determined using the method comparing 50 and $95 \%$ UDs at different multiplier values as described by Simpfendorfer et al. (2012). There were 9 groups to which this method was applied. For 3D analysis, each mean daily location had both a day and night depth value associated with it, based on the mean values during those times and dates for a total of 6 groups (2 time periods $\times 3$ species). The 2D analysis used the mean daily locations grouped by species for a total of 3 groups (1 time period $\times 3$ species). The smoothing factor matrices of these 9 groups were multiplied by integer values between 1 and 10, after which the standardized change in the ratio between the area/volume of the 50 and $95 \%$ UDs was plotted. The lowest multiplier value with the smallest change across all groups, which was 5, was applied to all smoothing factor matrices for further analysis and comparisons.

Core areas (defined by $50 \%$ probability contours) and extent of activity space (95\% probability contours) by species were calculated using the ' $k d e$ ' function in the R package ' $k s^{\prime}$ (Duong 2015). Area or volume was calculated for both $2 \mathrm{D}$ and 3D UDs, respectively, by gridding the space and determining the number of cells within that probability contour and multiplying by the size of each cell (Simpfendorfer et al. 2012). Volume in 3D UDs was truncated to only include depths $<0 \mathrm{~m}$. Areas of habitat use $>0 \mathrm{~m}$ were artefacts of the kernel smoothing, are not biologically realistic, and were excluded. When appropriate, overlap between UDs was calculated and then divided by the area/volume for their respective probability contours to obtain a proportion of overlapping UDs. When determining overlap, it was imperative that the size of the grids be the same to calculate this properly.

The 2D UDs were produced for sailfish by season and the total area for both core areas and extent of activity space were calculated. The 3D UDs were produced for sailfish by season individually for both day and night and the total volume for both core areas and extent of activity space were calculated as well for diel purposes.

Both 2D and 3D UDs were calculated for sailfish, blue marlin, and white marlin during the months of June-August combined. Total area and overlap between species for both core areas and the extent of activity space were calculated for these 2D UDs, as well as day and night 3D UDs for all species during these months. Total overlap was calculated by summing the overlap of day and night 3D UDs between species. The proportion of overlap in both $2 \mathrm{D}$ and $3 \mathrm{D}$ UDs were then compared between sailfish and the 2 marlin species by dividing the overlap by the total area/volume of the respective sailfish UDs.

\section{RESULTS}

PSATs were deployed on 78 billfish between 30 May 2003 and 1 July 2006. Of those tags, 26 met the criteria described above to be included in the analysis: 19 sailfish, 4 blue marlin, and 3 white marlin (Table 1). Fish were tagged between $31.64^{\circ}-32.49^{\circ} \mathrm{N}$ and $78.14^{\circ}-79.49^{\circ} \mathrm{W}$ (Fig. 1). Tags remained attached for variable times based on programmed release dates or early release due to attachment failure. On average, PSATs remained attached to sailfish for $95 \pm$ 15 d (SE; range: 19-243 d). Days the PSATs remained attached by season for sailfish were variable, with the lowest attachment times in spring $(19 \pm 3.7 \mathrm{~d}$; range: 3-43 $\left.\mathrm{d}_{;} \mathrm{n}=15 \mathrm{fish}\right)$, followed by winter (53 $\pm 19.6 \mathrm{~d}$; range: $23-90 \mathrm{~d} ; \mathrm{n}=3 \mathrm{fish})$, summer (56 $\pm 6.5 \mathrm{~d}$; range: 17-92 $\mathrm{d} ; \mathrm{n}=18 \mathrm{fish})$, and autumn (62 $\pm 14.6 \mathrm{~d}$; range: 14-92 $d_{;} n=6$ fish). On average, the PSATs remained attached on blue marlin for $76 \pm 15$ d (range: 51$108 \mathrm{~d}$ ) and on white marlin for $50 \pm 11 \mathrm{~d}$ (range: 29 $62 \mathrm{~d}$ ) (Table 1). Though the area where fish were tagged and released was relatively small, the pop-up locations for some tags were quite varied and distant from each other (Fig. 1). The pop-up locations for PSATs on sailfish were between $12.99^{\circ}-37.16^{\circ} \mathrm{N}$ and $63.63^{\circ}-80.33^{\circ} \mathrm{W}$, for blue marlin between $32.65^{\circ}-$ $39.71^{\circ} \mathrm{N}$ and $78.62-79.14^{\circ} \mathrm{W}$, and for white marlin between $32.19^{\circ}-38.49^{\circ} \mathrm{N}$ and $73.10^{\circ}-78.95^{\circ} \mathrm{W}$.

Of the 26 tags processed for mean daily locations, 5 did not converge using the light and temperature- 
Table 1. Tagging summary by species for sailfish (SF), blue marlin (BM), and white marlin (WM). LJFL: estimated lower jaw fork length of the tagged fish; (-) no estimate obtained. Movement is summarized by distance (dist.) traveled, which was calculated from the mean daily locations, as well as displacement (disp.) between the deployment and pop-off location

\begin{tabular}{|c|c|c|c|c|c|c|c|c|c|c|c|}
\hline \multirow{2}{*}{$\begin{array}{l}\text { PTT } \\
\text { tag no. }\end{array}$} & \multirow[t]{2}{*}{ Species } & \multirow{2}{*}{$\begin{array}{l}\text { LJFL } \\
(\mathrm{cm})\end{array}$} & \multicolumn{3}{|c|}{ — Deployment } & \multirow{2}{*}{$\begin{array}{c}\text { Date } \\
\text { (mm/dd/yy) }\end{array}$} & \multicolumn{2}{|c|}{ op-off } & \multirow{2}{*}{$\begin{array}{c}\text { Days at liberty/ } \\
\text { programmed }\end{array}$} & \multirow{2}{*}{$\begin{array}{c}\text { Dist. } \\
\text { traveled } \\
(\mathrm{km})\end{array}$} & \multirow{2}{*}{$\begin{array}{l}\text { Disp } \\
(\mathrm{km})\end{array}$} \\
\hline & & & $\begin{array}{c}\text { Date } \\
\text { (mm/dd/yy) }\end{array}$ & $\begin{array}{l}\text { Lat } \\
\left({ }^{\circ} \mathrm{N}\right)\end{array}$ & $\begin{array}{l}\text { Long } \\
\left({ }^{\circ} \mathrm{W}\right)\end{array}$ & & $\begin{array}{l}\text { Lat } \\
\left({ }^{\circ} \mathrm{N}\right)\end{array}$ & $\begin{array}{l}\text { Long } \\
\left({ }^{\circ} \mathrm{W}\right)\end{array}$ & & & \\
\hline 37080 & $\mathrm{SF}$ & - & $6 / 26 / 03$ & 32.12 & 78.95 & $7 / 22 / 03$ & 36.07 & 69.06 & $26 / 60$ & 1825 & 1011 \\
\hline 37081 & $\mathrm{SF}$ & 142 & $6 / 14 / 05$ & 31.64 & 78.78 & $10 / 14 / 05$ & 31.24 & 71.94 & $121 / 120$ & 6057 & 651 \\
\hline 37094 & SF & - & $5 / 30 / 03$ & 32.12 & 78.91 & 9/28/03 & 31.46 & 79.84 & $121 / 120$ & 3630 & 115 \\
\hline 39804 & $\mathrm{SF}$ & - & $7 / 12 / 03$ & 31.96 & 79.49 & 8/11/03 & 31.75 & 72.68 & $30 / 120$ & 1187 & 645 \\
\hline 39806 & $\mathrm{SF}$ & 122 & $5 / 24 / 04$ & 32.31 & 78.92 & $7 / 24 / 04$ & 32.87 & 71.09 & $60 / 60$ & 3454 & 737 \\
\hline 39820 & $\mathrm{SF}$ & - & $7 / 30 / 03$ & 31.94 & 79.29 & $1 / 23 / 04$ & 21.18 & 72.91 & $178 / 240$ & 11976 & 1354 \\
\hline 39821 & $\mathrm{SF}$ & 152 & 6/28/05 & 32.12 & 79.19 & $7 / 26 / 05$ & 31.90 & 80.28 & $27 / 180$ & 287 & 105 \\
\hline 46488 & $\mathrm{SF}$ & 127 & $6 / 3 / 06$ & 32.20 & 78.97 & 8/4/06 & 34.64 & 75.86 & $62 / 60$ & 1333 & 396 \\
\hline 46489 & $\mathrm{SF}$ & 145 & $6 / 25 / 04$ & 32.00 & 79.47 & $10 / 25 / 04$ & 37.16 & 70.31 & $122 / 120$ & 4355 & 1017 \\
\hline 46490 & SF & 114 & 6/3/06 & 32.34 & 78.97 & 8/5/06 & 29.09 & 78.15 & $63 / 60$ & 1216 & 371 \\
\hline 46495 & $\mathrm{SF}$ & 142 & 7/6/04 & 32.47 & 78.86 & 9/19/04 & 35.67 & 74.13 & $75 / 180$ & 3123 & 563 \\
\hline 46500 & $\mathrm{SF}$ & 157 & $8 / 12 / 04$ & 32.01 & 79.29 & 4/8/05 & 30.07 & 80.06 & $240 / 240$ & 9821 & 228 \\
\hline 55513 & SF & - & $5 / 19 / 05$ & 32.49 & 78.65 & 9/19/05 & 33.85 & 74.07 & $122 / 120$ & 5054 & 452 \\
\hline 55518 & SF & 145 & $7 / 26 / 05$ & 32.12 & 79.17 & $11 / 26 / 05$ & 30.17 & 80.25 & $122 / 120$ & 5056 & 241 \\
\hline 55520 & $\mathrm{SF}$ & 102 & $6 / 3 / 05$ & 32.46 & 78.67 & 8/5/05 & 36.58 & 72.61 & $62 / 180$ & 1555 & 720 \\
\hline 55528 & $\mathrm{SF}$ & 152 & $6 / 27 / 05$ & 31.96 & 79.30 & $9 / 12 / 05$ & 31.36 & 77.99 & $76 / 240$ & 2934 & 141 \\
\hline 55530 & $\mathrm{SF}$ & 152 & $6 / 27 / 05$ & 32.14 & 79.12 & $7 / 17 / 05$ & 33.96 & 75.93 & $19 / 240$ & 1305 & 360 \\
\hline 55533 & $\mathrm{SF}$ & 152 & $6 / 17 / 05$ & 32.01 & 78.14 & $2 / 16 / 06$ & 12.99 & 63.63 & $243 / 240$ & 17120 & 2583 \\
\hline 55534 & $\mathrm{SF}$ & 91 & $5 / 19 / 06$ & 32.24 & 79.01 & $6 / 23 / 06$ & 31.91 & 80.33 & $35 / 60$ & 1429 & 130 \\
\hline 37089 & $\mathrm{BM}$ & - & 6/16/03 & 32.09 & 78.84 & $9 / 16 / 03$ & 32.65 & 77.93 & $92 / 90$ & 3612 & 107 \\
\hline 39809 & $\mathrm{BM}$ & - & $5 / 30 / 03$ & 32.31 & 78.78 & $7 / 20 / 03$ & 37.19 & 71.73 & $51 / 120$ & 1975 & 843 \\
\hline 46498 & $\mathrm{BM}$ & 210 & 8/17/04 & 32.09 & 79.14 & $12 / 3 / 04$ & 35.48 & 73.57 & $108 / 180$ & 3810 & 638 \\
\hline 55531 & $\mathrm{BM}$ & 168 & $5 / 20 / 06$ & 32.42 & 78.62 & $7 / 13 / 06$ & 39.71 & 73.27 & $54 / 60$ & 2293 & 943 \\
\hline 37088 & WM & - & 6/2/04 & 32.46 & 78.82 & $7 / 2 / 04$ & 32.19 & 78.95 & $29 / 30$ & 471 & 32 \\
\hline 37090 & WM & 137 & $7 / 1 / 06$ & 32.12 & 79.19 & $9 / 1 / 06$ & 36.92 & 73.92 & $62 / 60$ & 3122 & 720 \\
\hline 46497 & WM & 170 & $6 / 2 / 06$ & 32.16 & 78.96 & $8 / 2 / 06$ & 38.49 & 73.10 & $60 / 61$ & 3047 & 882 \\
\hline
\end{tabular}

based model ('ukfsst'), requiring the use of the simpler light-only model ('kftrack'). There was a wide range of movement patterns among the tagged fishes, some heavily dependent on the amount of time the tag was attached (Figs. S1-S26 in the Supplement at www.intres.com/articles/suppl/m638p137_supp.pdf). Nearly all fish showed some degree of both coastal and offshore movements but to varying degrees, with certain fish having predominantly localized, coastal movements (Fig. 2A), predominantly coastal movements with some offshore excursions (Fig. 2B), directed offshore movements (Fig. 2C), and large-scale migration south after exhibiting a variety of movements throughout the tag attachment (Fig. 2D).

Throughout the tag attachment period, sailfish exhibited vertical diel movement patterns (ANOVA: $F=16.13, \mathrm{df}=1,36, \mathrm{p}=0.0003)$, occupying deeper depths during the day and shallower depths at night (Fig. 3A). Sailfish also exhibited seasonal differences between depth at both day $(F=4.942, \mathrm{df}=3,38, \mathrm{p}=$ $0.00539)$ and night $(F=2.993, \mathrm{df}=3,38, \mathrm{p}=0.0427)$ (Fig. 3A). Depth during the day was progressively deeper as the year went on, with the autumn and winter being significantly deeper compared to the spring (Tukey's HSD: $\mathrm{p}=0.025$ and 0.037 , respectively). While the ANOVA showed significant differences between depths at night by season, the post hoc test did not differentiate between the seasons (Tukey's HSD: $\mathrm{p}>0.05$ for all comparisons).

In the comparison among species during JuneAugust, there were significant differences in depth for both day (ANOVA: $F=3.984, \mathrm{df}=2,23, \mathrm{p}=$ $0.0327)$ and night $(F=6.096, \mathrm{df}=2,23, \mathrm{p}=0.00751)$ (Fig. 3B). Sailfish were at significantly shallower depths than blue marlin and white marlin at night (Tukey's HSD: $p=0.032$ and 0.042 , respectively), though post hoc tests did not differentiate between species for depth during the day (Tukey's HSD: p > 0.05 for all comparisons).

Sailfish showed directional UDs between seasons, with spring and summer indicating a southwest/ northeast orientation, while autumn and winter both showed a northwest/southeast orientation (Figs. 4 \& 5). Even though there were differences between the extents of activity space of the UDs, the core areas showed a large amount of overlap during spring- 


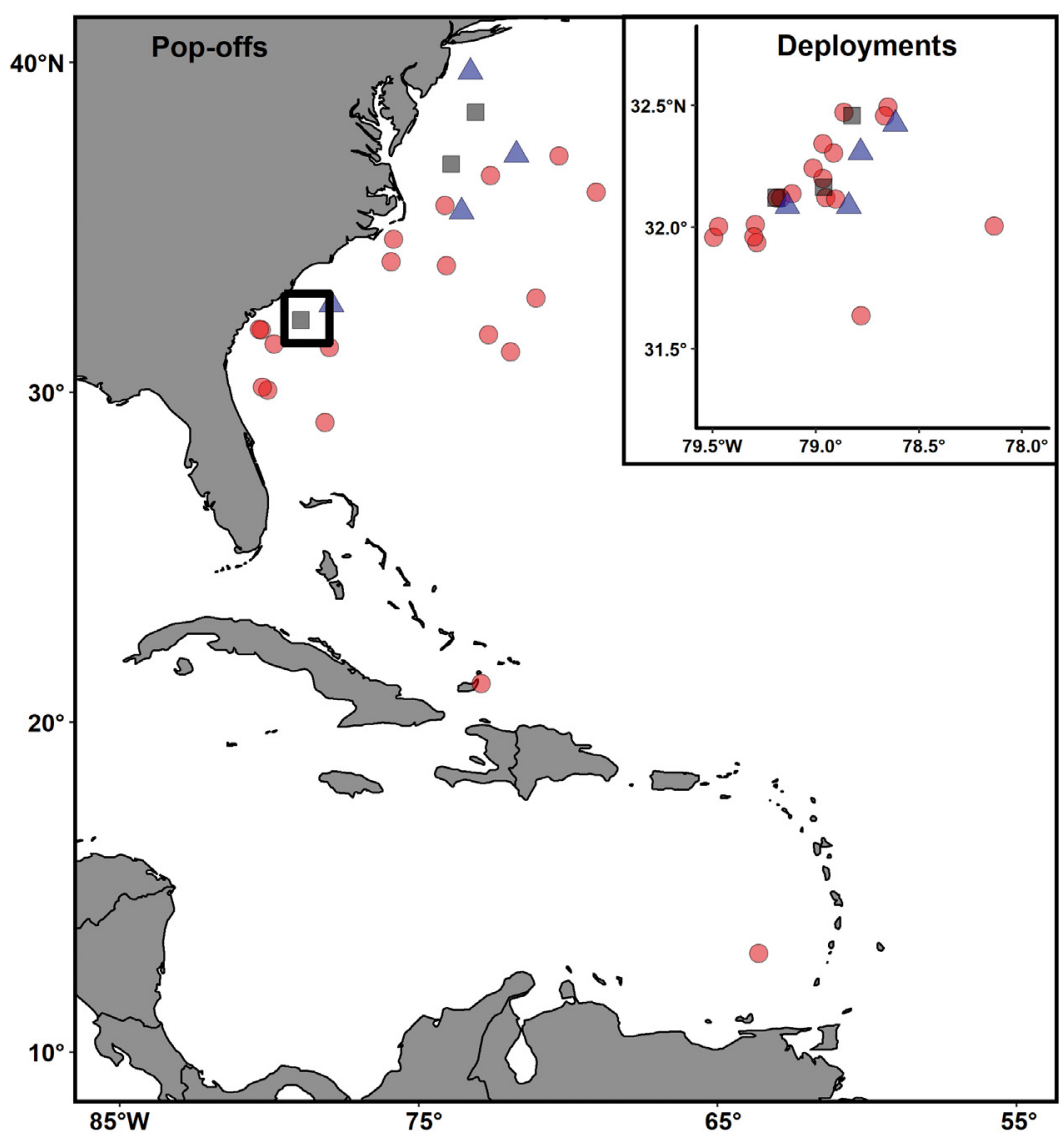

Fig. 1. Deployment locations (inset) and pop-off locations of pop-off satellite archival tags on sailfish (red circles), blue marlin (blue triangles), and white marlin (black squares). The black square in the pop-off portion of the map identifies the area of the inset map

autumn. Winter was the only season in which the core area was oceanic and moved away from the coastal Carolinas. During spring and summer, when south of Cape Hatteras, North Carolina $\left(35.22^{\circ} \mathrm{N}\right)$, sailfish stayed mainly near the continental shelf and slope. When north of Cape Hatteras, sailfish utilized oceanic waters off the continental slope in the general direction in which the Gulf Stream is deflected. During the autumn and winter, the UDs followed the coast of Florida, or further south along the Bahamas and Lesser Antilles archipelago. In fact, all 3 tags that were still attached in the winter months were along these islands from the Bahamas to northern South America.

During June-August, the sailfish UD showed a southwest/northeast orientation. Sailfish and blue marlin, for the combined months, had minimal overlap with core use areas, but nearly $50 \%$ overlap between extents of activity space for both 2D and 3D UDs (Table 2, Fig. 6A). Sailfish and white marlin showed a different pattern, with nearly the same amount of overlap in the extents of activity space as blue marlin had with sailfish, but a greater amount of overlap in the core area (Table 2, Fig. 6B).

\section{DISCUSSION}

The results of this study provide new information that can fill existing gaps in our understanding of spatiotemporal movement patterns of sailfish in the western North Atlantic. Even though more streamer tags have been deployed and recaptured from sailfish than any other istiophorid species, the limitations of this tagging method still leave significant gaps in our understanding of their horizontal and vertical movements (Ortiz et al. 2003, Orbesen et al. 2008). This study provides new information on billfish movements and oceanic habitat use, especially in relation to tagging locations, dates of deployment, and length of observations. To our knowledge, this study is the first attempt to use 3D modelling of UDs for istiophorid billfish with data from PSATs, which more appropriately characterizes horizontal and vertical movements. Because sailfish travel large horizontal distances and there is light-based geolocation uncertainty, this study is meant to be a conservative estimate of broad-scale spatial and temporal movements and habitat use. Finally, this tagging study also provides context of spatial and temporal habitat compared to other istiophorid billfish caught in the same general area and time of year.

Though the areas of the seasonal UDs were extensive, core use areas showed an affinity of the sailfish for coastal waters. This was evident even with the longest tracked individuals, which closely followed the Antilles Archipelago southward to South America. Coastal affinity and no trans-Atlantic or transequatorial movement is consistent with other streamer and electronic tagging studies on this species (Prince et al. 2010, Lam et al. 2016). Conversely, the extent of activity space showed that sailfish are not limited to coastal environments, as they made more oceanic movements north of Cape Hatteras, North Carolina. These movements could potentially be related to the Gulf Stream current and warmer 

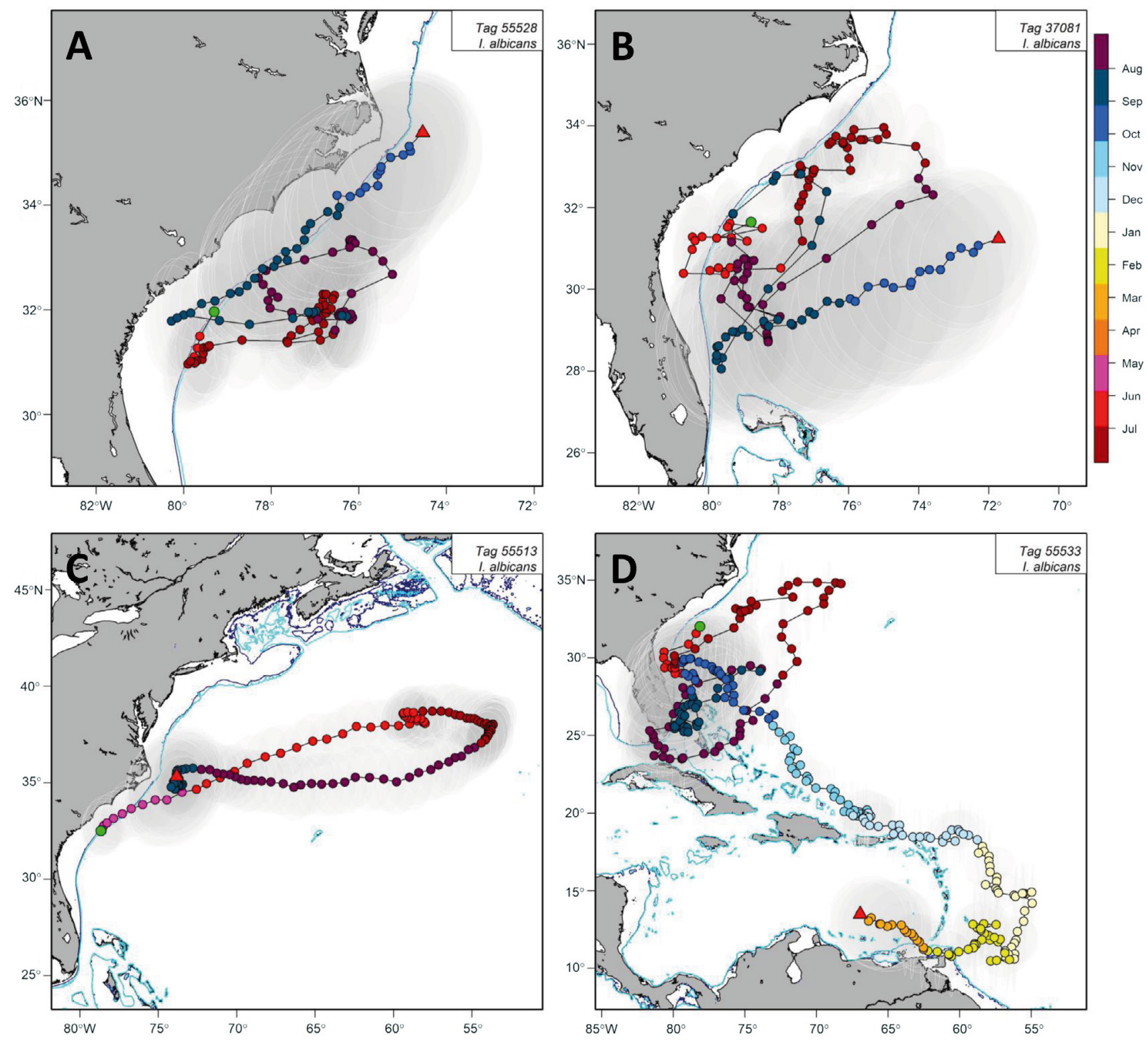

Fig. 2. Representative tracks composed of mean daily locations of sailfish, showing (A) predominantly localized, coastal movements, (B) predominantly coastal movements with some offshore excursions, (C) directed offshore movements, and (D) large-scale migration south after exhibiting a variety of movements throughout the tag attachment. Gray circles: $95 \%$ confidence interval of each mean daily location

waters as they deflect to the east, north of Cape Hatteras. Lam et al. (2016) also observed movements from sailfish in the Gulf of Mexico following similar, predominantly coastal patterns, with occasional ventures to more oceanic waters.

This study also confirms transboundary movement of sailfish across management zones, as tagged fish occupied similar areas as others tagged in the Caribbean, Florida East Coast, and Gulf of Mexico management areas of the western North Atlantic (Orbesen et al. 2008, Prince et al. 2010, Lam et al. 2016).
These movements also coincide with hypothesized spawning areas, most notably the east coast and Straits of Florida, the South Atlantic Bight, the Bahamas, and even off the northern coast of South America (Voss 1953, Gehringer 1956, Post et al. 1997, Serafy et al. 2003, Richardson et al. 2009). This movement, if related to these spawning areas, could explain the potential connectivity between the widely spread stock in the northwestern Atlantic, as shown by previous studies using genetic markers and tags (Orbesen et al. 2008, ICCAT 2016, Lam et al. 2016). 

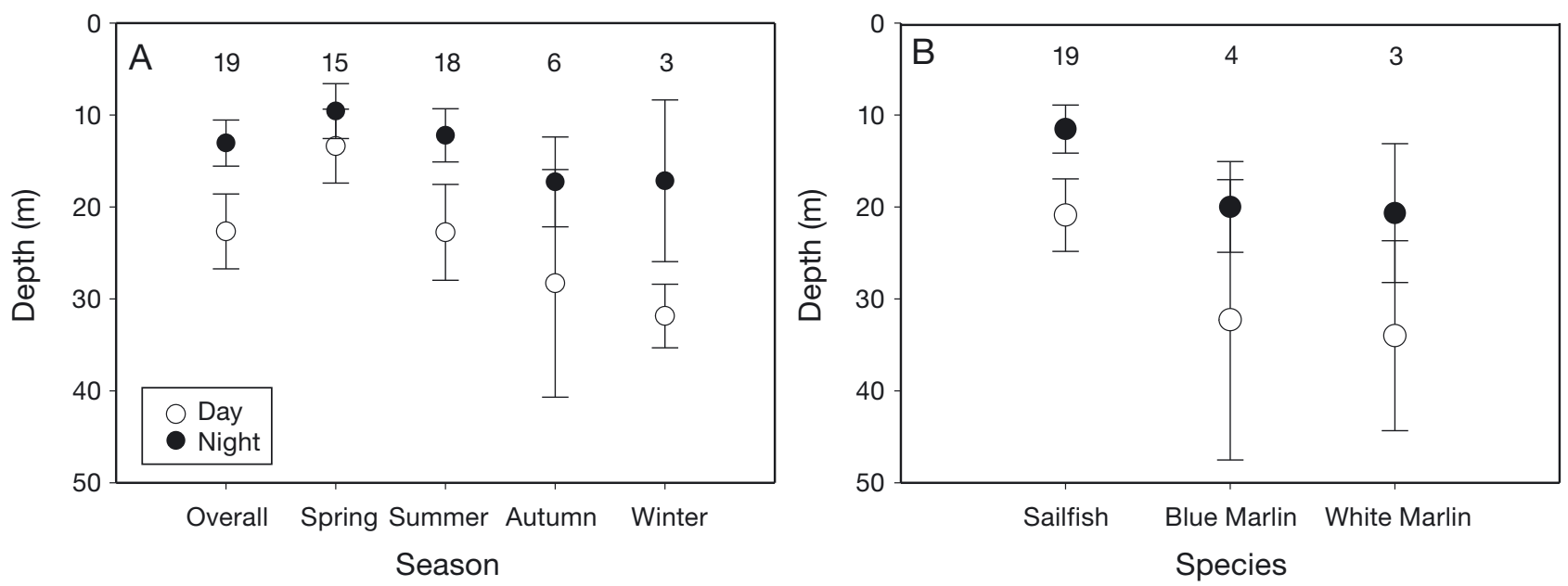

Fig. 3. Day and night differences between depth of (A) sailfish, overall and by season and (B) among sailfish, blue marlin, and white marlin during June-August. Numbers: sample size; error bars: $\pm 2 \mathrm{SE}$
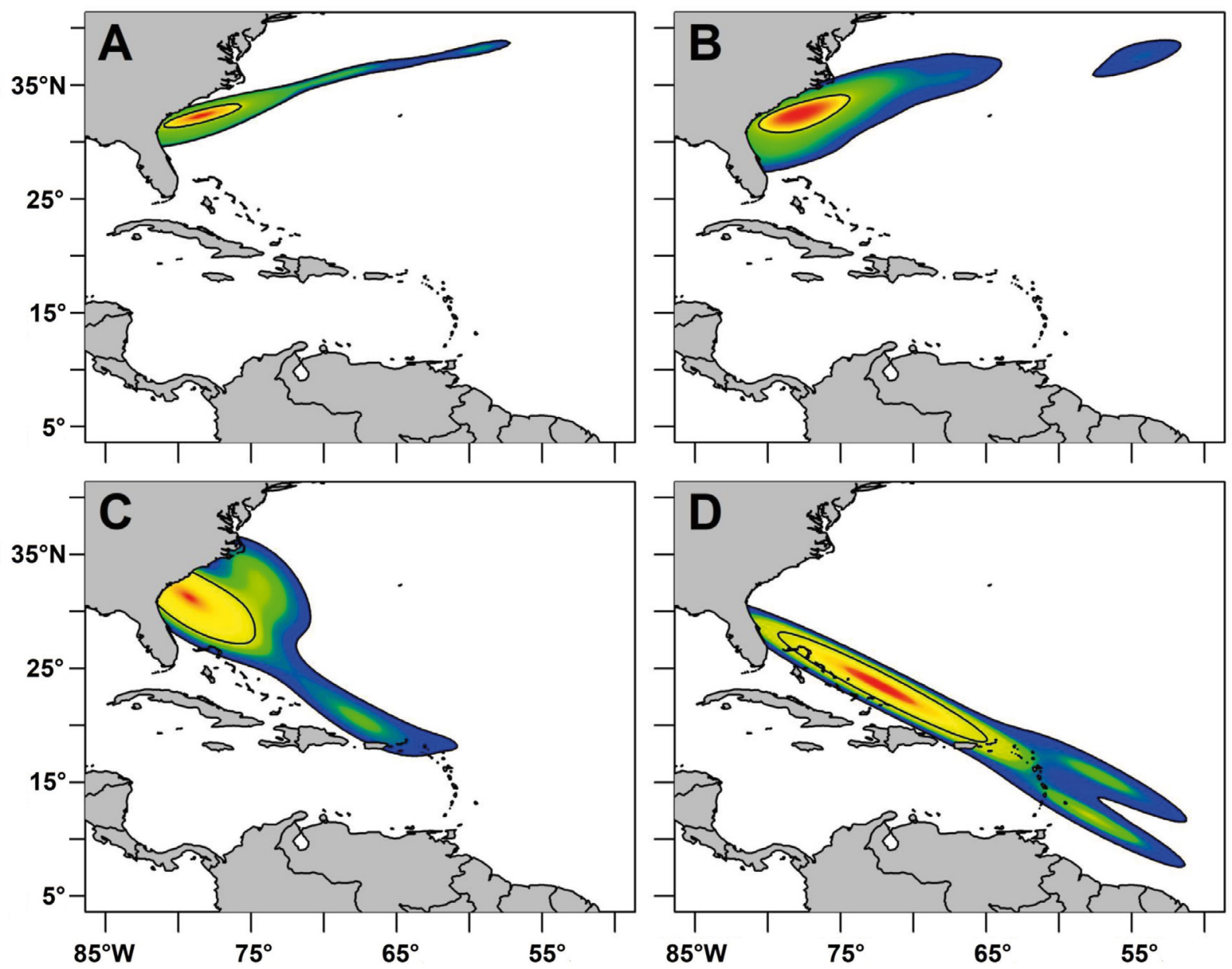

Fig. 4. Two-dimensional utilization distributions (UDs) for sailfish by season, showing (A) spring, (B) summer, (C) autumn, and (D) winter. Inner areas bounded by a black line represent the core (50\% probability of encountering a fish), while the larger, outer marked areas bounded by a black line represent the extent of activity space ( $95 \%$ probability of encountering a fish).

Colors represent $1 \%$ gradations of the UDs from $1 \%$ (red) to $95 \%$ (blue) 
A

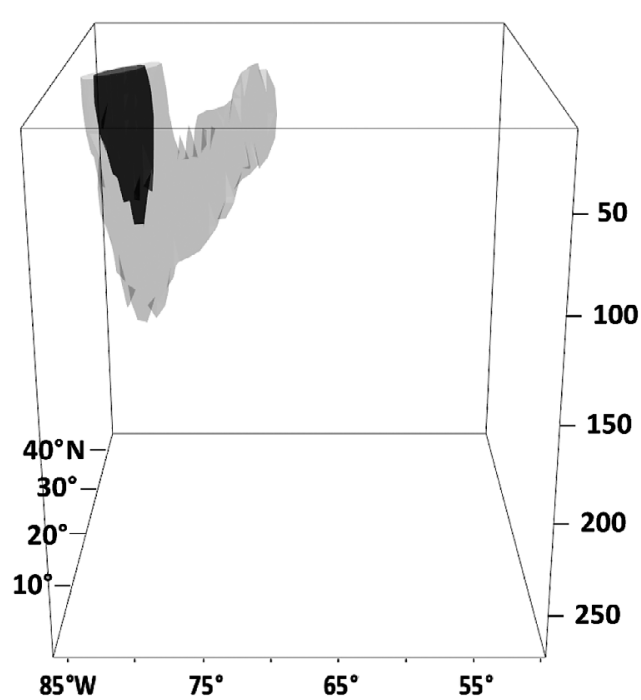

C

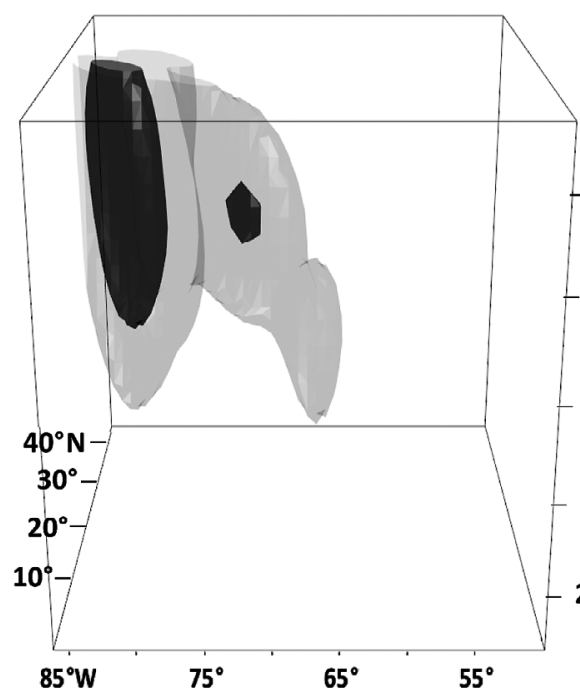

B

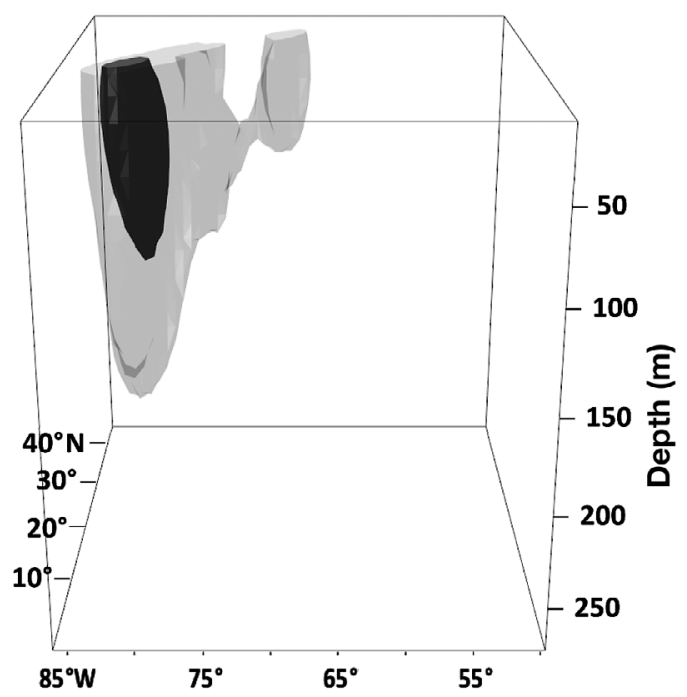

D

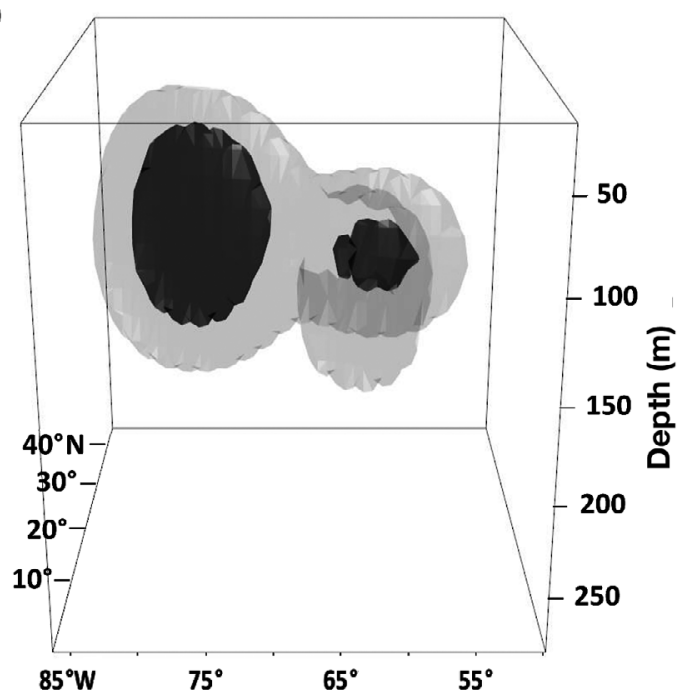

Fig. 5. Three-dimensional utilization distributions for sailfish by season, showing (A) spring, (B) summer, (C) autumn, and (D) winter. Darker inner area represents the core (50\% probability of encountering a fish), while the lighter and larger, outer area represents the extent of activity space ( $95 \%$ probability of encountering a fish)

Table 2. Characteristics of utilization distributions (UDs) for sailfish, and comparisons of sailfish with blue marlin and white marlin. Both 2-dimensional (2D) and 3-dimensional (3D) values were calculated; 3D values consist of daytime only UDs, night time only UDs, and the combination of the $2 ; 2 \mathrm{D}$ areas are in $\mathrm{m}^{2}$, while 3 -dimensional volumes are in $\mathrm{m}^{3}$

\begin{tabular}{|c|c|c|c|c|}
\hline & \multirow[t]{2}{*}{$2 \mathrm{D}$} & \multicolumn{3}{|c|}{$-3 \mathrm{D}-$} \\
\hline & & Combined & Day & Night \\
\hline \multicolumn{5}{|l|}{ Sailfish } \\
\hline Core $(50 \%)$ area/volume & $1.11 \times 10^{11}$ & $95.6 \times 10^{11}$ & $61.5 \times 10^{11}$ & $34.1 \times 10^{11}$ \\
\hline Extent of activity space (95\%) area/volume & $9.74 \times 10^{11}$ & $876 \times 10^{11}$ & $518 \times 10^{11}$ & $358 \times 10^{11}$ \\
\hline \multicolumn{5}{|l|}{ Sailfish/blue marlin comparison } \\
\hline Core overlap proportion & 0.01 & 0.04 & 0.04 & 0.04 \\
\hline Extent of activity space overlap proportion & 0.47 & 0.55 & 0.51 & 0.62 \\
\hline \multicolumn{5}{|l|}{ Sailfish/white marlin comparison } \\
\hline Core overlap proportion & 0.56 & 0.38 & 0.34 & 0.44 \\
\hline Extent of activity space overlap proportion & 0.56 & 0.49 & 0.47 & 0.50 \\
\hline
\end{tabular}



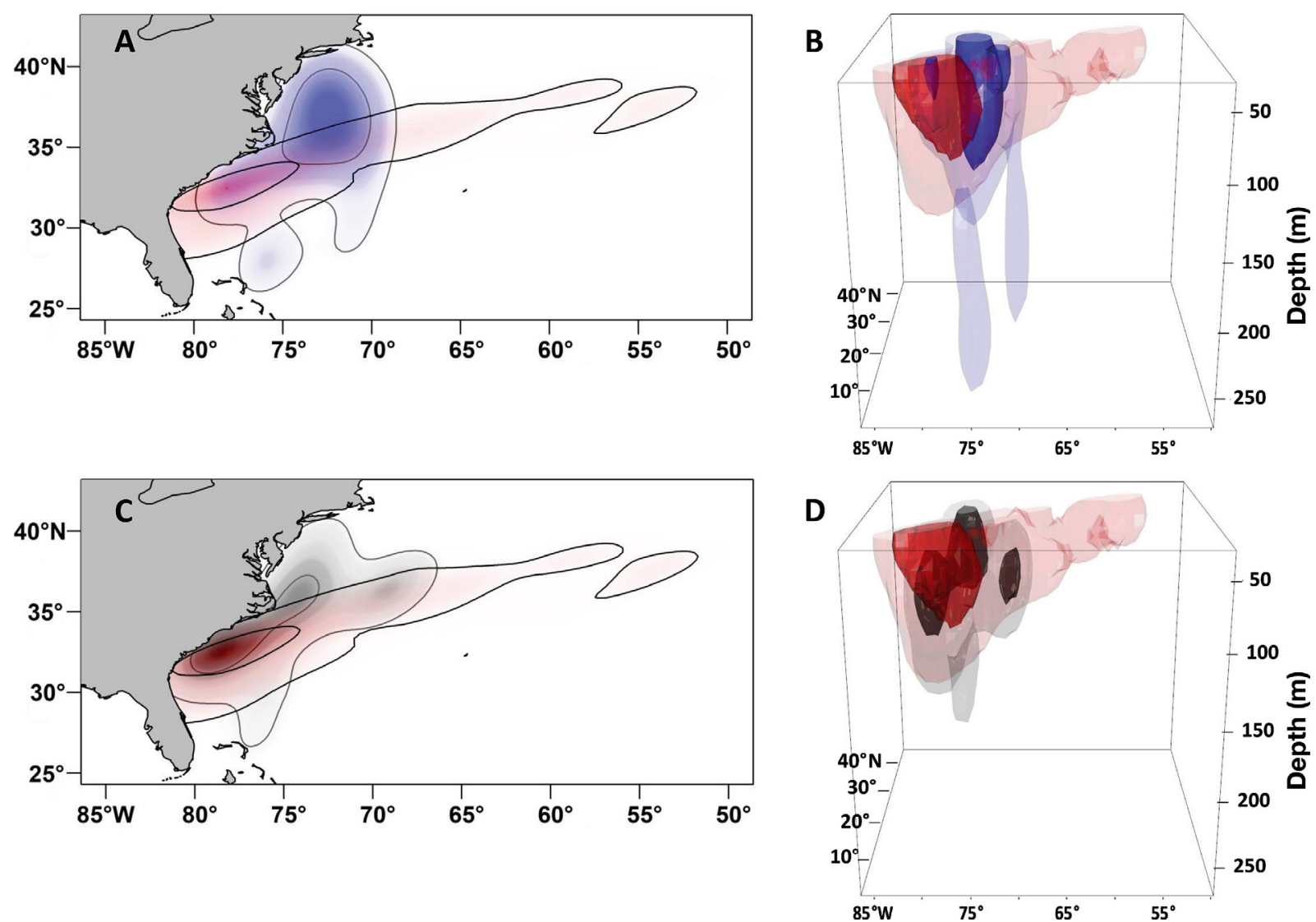

Fig. 6. Overlap between (A,C) 2-dimensional and (B,D) 3-dimensional utilization distributions for sailfish (red), blue marlin (blue), and white marlin (black). Inner, darker area represents the core (50\% probability of encountering a fish), while the outer, lighter area represents the extent of activity space ( $95 \%$ probability of encountering a fish)

It has also been hypothesized that these movements may correspond to annual migratory behavior in sailfish (Ortiz et al. 2003, Lam et al. 2016). However, due to the limited number of observations, this study was not able to further test this hypothesis. The 2 fish with the longest tag deployments $(240$ and 243 d) showed different movement patterns. One tag popped off only $228 \mathrm{~km}$ from where it was deployed, indicating fidelity to that area after movement to the south, while the other fish had the largest displacement $(2583 \mathrm{~km})$, with the tag popping off before evidence of a return was apparent. The tags were not deployed long enough ( $1 \mathrm{yr}$ or greater) to conclude that those individuals with large-scale movements (most notably all 3 fish with tags still attached in the winter that went south) returned annually.

Sailfish and other istiophorid billfishes are known to use multiple depths within the water column (Kerstetter et al. 2011, Vaudo et al. 2018). Because a diel pattern was observed in the current study, a third dimension of depth was added for analysis to better characterize the habitat utilization of these tagged fishes. Daytime and nighttime UDs calculated by season for sailfish, and between species, showed a compression of the nighttime UD towards the surface, which coincides with the diel movement patterns of billfish utilizing the surface waters during the night (Prince et al. 2005, Prince \& Goodyear 2006, Sippel et al. 2007, Hoolihan et al. 2011). There was also a change in depth by season for sailfish. There are many potential causes for this type of behavior, including motivation for movement (i.e. migratory vs. foraging), temperature, oxygen, prey, light, currents, competition, or predators, and because many of these factors are correlated it is difficult to decouple their influence (Brill \& Lutcavage 2001, Prince \& Goodyear 2006, Prince et al. 2010, Hoolihan et al. 2011).

Comparisons between species could only be made between June and August. This was because fewer tags were deployed on blue marlin and white marlin than sailfish, with the tagging primarily taking place in these months. This factor was compounded with 
pop-off times being relatively short (120 d or less), leading to fewer tags of blue and white marlin being attached in months outside of June-August. While all 3 species were caught in general proximity to each other, the overlap of UDs between sailfish and blue marlin or white marlin was quite different. There was minimal overlap between the core areas of sailfish and blue marlin during June-August, as shown by both 2D and 3D UDs. Blue marlin exhibited more widespread movements, being less constrained by temperature or distance from shore than sailfish (Prince \& Goodyear 2006, Goodyear et al. 2008). This indicates that, while they were tagged in a similar area and time, blue marlin were more transitory, while sailfish showed relative fidelity to an area during these months. It is also worth noting that when comparing between 2D and 3D UDs, there is little difference between their interpretations when minimal horizontal overlap occurs. White marlin, conversely, showed a much greater degree of overlap with sailfish in the core areas during June-August. There was also a greater degree in overlap of the core areas of sailfish and white marlin with $2 \mathrm{D}$ versus 3D UDs. This suggests that while the 2 species may occupy similar horizontal locations, the difference in depths observed could be a means of partitioning habitat to limit competition. Simpfendorfer et al. (2012) found similar results in European eel Anguilla anguilla, attributing it to an overestimation of shared space when an animal lives in a 3D habitat, but is portrayed in 2 dimensions.

While the use of kernel density estimators to produce UDs have the potential to introduce biases, the scale and scope of the findings from the current study aimed to minimize those potential biases (Winton et al. 2018). By analyzing UDs in 3 mo time periods, the number of mean daily locations between individuals are relatively consistent within the time period. This relatively even dispersal of locations among individuals reduces autocorrelative effects that can occur if some individuals have greater influence on the UD due to having more recorded locations than others (Whitehead \& Jonsen 2013). While UDs may not be appropriate for fine-scale movement patterns, the broadscale movement patterns would be unaffected, showing general orientation of movement seasonally or by species, by core areas, and for coastal versus oceanic movements. Finally, when making comparisons between 2D and 3D overlap of UDs, the same mean daily locations are used, with the only difference being an inclusion of a depth term within the 3D analysis. Therefore, any biases that may be present are consistent between the 2 analyses.
In summary, this study highlights the need to incorporate depth to appropriately characterize habitat utilization of species for both ecological and management purposes, while demonstrating a means to do so using 3D kernel estimation based on PSAT tagged fish. Complex seasonal patterns in sailfish were observed using this method, as well as potential ecological interactions among species. By considering horizontal, vertical, as well as temporal aspects of the movements, these behaviors can be tied to environmental or ecological variables to increase our understanding of drivers for these movements. In the future, these results could be applied to address uncertainties in management, such as characterization of stock structure, providing correction factors for indices of abundance, and characterizing vulnerability to fishing gear. This improved representation of movement provides a greater understanding for both conservation and ecological purposes.

Acknowledgements. We acknowledge the efforts of George Sedberry and Josh Loefer who were the original investigators on the grants that provide funding for this work. We also thank John Geddings, Scott Meister, Paulette Mikell, and Dan Russ for field assistance. We thank the reviewers, who brought constructive comments that enabled more clarity in the final manuscript. The research described herein complies with all current laws and animal welfare policies of the United States. Permits for the capture and tagging of billfish were provided by the US Department of Commerce, National Oceanic and Atmospheric Administration Office of Sustainable Fisheries (Permit no. HMS-SRP-02-001 and HMS-SRP03-02). Funding was provided by NOAA Fisheries, grant numbers NA07FL0497, NA16FL2814, and NA03NMF 4720321. We would also like to thank the owners and captains of sport fishing vessels participating in the SC Governor's Cup Billfishing Series who graciously donated vessel time for staff to deploy the tags during tournaments as well as on private charters. Finally, we owe deep debts of gratitude to The Guy Harvey Ocean Foundation and the SC Governor's Cup Billfishing Series for their direct contribution of funds to bring this work to publication. This is contribution number 818 of the South Carolina Marine Resources Division.

\section{LITERATURE CITED}

Amante C, Eakins BW (2009) ETopo1 1 arc-minute global relief model: procedures, data sources and analysis. NOAA Tech Memo NESDIS NDGC-24

Bivand R, Lewin-Koh N (2015) maptools: tools for reading and handling spatial objects. $\mathrm{R}$ package version $0.8-34$. http://CRAN.R-project.org/package=maptools

Brill RW, Lutcavage M (2001) Understanding environmental influences on movements and depth distributions of tunas and billfishes can significantly improve population assessments. Am Fish Soc Symp 25:179-198

Brooks DA, Bane JM Jr (1978) Gulf Stream deflection by a bottom feature off Charleston, South Carolina. Science 201:1225-1226 
Carpenter KE (ed) (2002) The living marine resources of the western Central Atlantic, Vol 2: bony fishes part 2 (Opistognathidae to Molidae), sea turtles and marine mammals. FAO, Rome

Collette BB, McDowell JR, Graves JE (2006) Phylogeny of recent billfishes (Xiphioidei). Bull Mar Sci 79:455-468

Duong T (2015) ks: kernel smoothing. R package version 1.9.4. http://CRAN.R-project.org/package=ks

Galuardi B (2010) analyzepsat. R package version 3.1. https: //github.com/positioning/kalmanfilter/wiki/Analyzepsat

Galuardi B, Royer F, Golet W, Logan J, Nielson J, Lutcavage M (2010) Complex migration routes of Atlantic bluefin tuna question current population structure paradigm. Can J Fish Aquat Sci 67:966-976

Gehringer JW (1956) Observations on the development of the Atlantic sailfish Istiophorus americanus (Cuvier): with notes on an unidentified species of istiophorid. Fish Bull 57:139-171

Goodyear CP, Luo J, Prince ED, Hoolihan JP, Snodgrass D, Orbesen ES, Serafy JE (2008) Vertical habitat use of Atlantic blue marlin Makaira nigricans: interaction with pelagic longline gear. Mar Ecol Prog Ser 365:233-245

Hijmans RJ (2015) geosphere: spherical trigonometry. R package version 1.3-13. http://CRAN.R-project.org/ package $=$ geosphere

Hoolihan JP, Luo J, Richardson DE, Snodgrass D, Orbesen ES, Prince ED (2009) Vertical movement rate estimates for Atlantic istiophorid billfishes derived from high resolution pop-up satellite archival data. Bull Mar Sci 84:257-264

Hoolihan JP, Luo J, Goodyear CP, Orbesen ES, Prince ED (2011) Vertical habitat use of sailfish (Istiophorus platypterus) in the Atlantic and eastern Pacific, derived from pop-up satellite archival tag data. Fish Oceanogr 20: 192-205

ICCAT (International Commission for the Conservation of Atlantic Tunas) (2016) Report of the 2016 ICCAT sailfish stock assessment. Sailfish stock assessment meeting, 30 May-3 Jun 2016, Miami, FL

Johnson DS, London JM, Lea MA, Durban JW (2008) Continuous-time correlated random walk model for animal telemetry data. Ecology 89:1208-1215

Kerstetter DW, Bayse SM, Fenton JL, Graves JE (2011) Sailfish habitat utilization and vertical movements in the southern Gulf of Mexico and Florida Straits. Mar Coast Fish 3:353-365

Lam CH, Nielsen A, Sibert JR (2008) Improving light and temperature based geolocation by unscented Kalman filtering. Fish Res 91:15-25

Lam CH, Galuardi B, Mendillo A, Chandler E, Lutcavage ME (2016) Sailfish migrations connect productive coastal areas in the West Atlantic Ocean. Sci Rep 6:38163

Loefer JK, Sedberry GR, Russ DC, Geddings JE, Weinbach P, McGovern JC (2007) Tagging of pelagic predators in the Charleston Bump Complex: final report \#NA16FL2814. National Marine Fisheries Service, Silver Spring, MD

Kynch PD, Shertzer KW, Latour RJ (2012) Performance of methods used to estimate indices of abundance for highly migratory species. Fish Res 125-126:27-39

Nielsen A, Sibert JR (2007) State-space model for lightbased tracking of marine animals. Can J Fish Aquat Sci 64:1055-1068

Nielsen A, Sibert JR, Ancheta J, Galuardi B, Lam CH (2012) ukfsst: Kalman filter tracking including sea surface temperature. $\mathrm{R}$ package version 0.3

Orbesen ES, Hoolihan JP, Serafy JE, Snodgrass D, Peel EM, Prince ED (2008) Transboundary movement of Atlantic istiophorid billfishes among international and US domes- tic management areas inferred from mark-recapture studies. Mar Fish Rev 70:14-23

Ortiz M, Prince ED, Serafy JE, Holts DB and others (2003) Global overview of the major constituent-based billfish tagging programs and their results since 1954. Mar Freshw Res 54:489-507

Post JT, Serafy JE, Ault JS, Capo TR, deSylva DP (1997) Field and laboratory observations on larval Atlantic sailfish (Istiophorus platypterus) and swordfish (Xiphias gladius). Bull Mar Sci 60:1026-1034

* Prince ED, Goodyear CP (2006) Hypoxia-based habitat compression of tropical pelagic fishes. Fish Oceanogr 15: 451-464

Prince ED, Cowen RK, Orbesen ES, Luthy SA, Llopiz JK, Richardson DE, Serafy JE (2005) Movements and spawning of white marlin (Tetrapturus albidus) and blue marlin (Makaira nigricans) off Punta Cana, Dominican Republic. Fish Bull 103:659-669

* Prince ED, Luo J, Goodyear P, Hoolihan JP and others (2010) Ocean scale hypoxia-based habitat compression of Atlantic istiophorid billfishes. Fish Oceanogr 19: 448-462

R Core Team (2019) R: a language and environment for statistical computing. R Foundation for Statistical Computing, Vienna

Restrepo V, Prince ED, Scott GP, Uozumi Y (2003) ICCAT stock assessments of Atlantic billfish. Mar Freshw Res 54: 361-367

Richardson DE, Cowen RK, Prince ED, Sponaugle S (2009) Importance of the Straits of Florida spawning ground to Atlantic sailfish (Istiophorus platypterus) and blue marlin (Makaira nigricans). Fish Oceanogr 18:402-418

* Sedberry G, Loefer J (2001) Satellite tracking of swordfish, Xiphias gladius, off the eastern United States. Mar Biol 139:355-360

Serafy JE, Cowen RK, Paris CB, Capo TR, Luthy SA (2003) Evidence of blue marlin, Makaira nigricans, spawning in the vicinity of Exuma Sound, Bahamas. Mar Freshw Res 54:299-306

* Sibert JR, Musyl MK, Brill RW (2003) Horizontal movements of bigeye tuna near Hawaii from archival tagging data. Fish Oceanogr 12:141-151

Simpfendorfer CA, Olsen EM, Heupel MR, Moland E (2012) Three-dimensional kernel utilization distributions improve estimates of space use in aquatic animals. Can J Fish Aquat Sci 69:565-572

* Sippel TJ, Davie PS, Holdsworth JC, Block BA (2007) Striped marlin (Tetrapturus audax) movements and habitat utilization during a summer and autumn in the Southwest Pacific Ocean. Fish Oceanogr 16:459-472

*Vaudo JJ, Byrne ME, Wetherbee BM, Harvey GM, Mendillo A Jr, Shivji MS (2018) Horizontal and vertical movements of white marlin, Kajikia albida, tagged off the Yucatán Peninsula. ICES J Mar Sci 75:844-857

Voss GL (1953) A contribution to the life history and biology of the sailfish, Istiophorus americanus Cuv. and Val., in Florida waters. Bull Mar Sci 3:206-240

* Whitehead H, Jonsen ID (2013) Inferring animal densities from tracking data using Markov chains. PLOS ONE 8: e60901

*Winton MV, Fay G, Haas HL, Arendt M and others (2018) Estimating the distribution and relative density of satellite-tagged loggerhead sea turtles using geostatistical mixed effect models. Mar Ecol Prog Ser 586:217-232

K Zhu L, Weng W (2007) Catadioptric stereo-vision system for the real-time monitoring of 3D behavior in aquatic animals. Physiol Behav 91:106-119 